\title{
CONSIDERACIONES SOBRE UN BORRADOR QUE SIRVIÓ PARA LA EDICIÓN DE 1780 DEL DE REBUS GESTIS CAROLI $V$ DE GINÉS DE SEPÚLVEDA
}

\author{
Matilde Conde Salazar (CSIC) Y \\ M.a José López de Ayala y Genovés (UNED)
}

En la Real Academia de la Historia, dentro de un manuscrito que contiene la traducción al castellano de la obra de Juan Ginés de Sepúlveda De rebus gestis Caroli $V$, se encuentra otro manuscrito titulado Diccionario militar para la traducción de Sepúlveda cuya transcripción realizamos en su momento y del que publicamos, ordenada y clasificada, la parte que corresponde estrictamente a «Diccionario»'. Este manuscrito contiene, además, tres folios con notas referentes a la traducción y con indicación de las páginas de la edición de la Academia de la Historia ${ }^{2}$, que corresponden a los catorce primeros libros.

Analizando más detenidamente estas notas, pudimos observar que el autor de las mismas, aunque utilizaba la obra de Sepúlveda, se había permitido una serie de interpretaciones a la hora de citar el texto latino que constituían, en alguna medida, una reelaboración del mismo, por lo que nos ha parecido interesante dedicarles una mayor atención. En efecto, cuando el traductor recoge en sus notas el texto de Ginés de Sepúlveda con excesiva frecuencia, no se ajusta

1 M. J. López de Ayala y M. Conde, «Diccionario militar para la traducción del De rebus gestis Caroli $V$ de J. G. de Sepúlveda*, Epos 10, 1994, 33-50.

2 Juan Ginés de Sepúlveda, De rebus gestis Caroli V, Madrid 1780. 
al original que sin duda tiene delante, sino que introduce variantes o modificaciones de diferente tipo. Partiendo de este presupuesto y habiendo considerado los ejemplos ${ }^{3}$ recogidos en el manuscrito, que atañen a los catorce primeros libros, se ofrece un estudio de los distintos tipos de variaciones que presentan con respecto al original agrupados en tomo a un esquema que recoge:

- Cambios

- Sustituciones

- Omisiones

- Addenda

- Reelaboraciones

- Reinterpretaciones

\section{CAmbIOS:}

\section{En el orden de palabras}

- I 154: Industria in bellis gerendis ${ }^{5}$ [in bellis gerendis industria].

- II 23: Ronquillum [unum ex quattuor aulicis praetoribus] cum praesidio equitum ducentorum triginta mittunt *ad motum popularium suprimen$d u m$ *. Se omite una parte del texto original. Tanto en la edición de Rodríguez Peregrina ${ }^{6}$, como en la de la Real Academia de la Historia y en los otros ma-

${ }^{3}$ Se ha realizado un recorrido minucioso a través del manuscrito completo que se encuentra en la Academia de la Historia, confrontándolo con el original de Ginés de Sepúlveda de donde fue tomado.

Sobre estos ejemplos pueden hacerse diversas incursiones; a traves de la lectura de un contexto más amplio podemos entender, explicar y, en algunos casos, justificar lo que contienen estas páginas del manuscrito y que deben tenerse en cuenta a la hora de la traducción del texto.

- El número en romanos indica el libro en que se encuentra la cita; la numeración árabe se refiere al capítulo dentro del libro.

5 Consideramos imprescindible para dar lectura y comprensión a lo que se ofrece, tener en cuenta lo siguiente:

1. El texto que presentamos en cursiva normal es el que aparece en las notas y coincide con el texto de Sepúlveda.

2. En cursiva, entre corchetes [...] texto de Ginés de Sepúlveda que no aparece en las notas o que es diferente respecto a las notas.

3. En cursiva, entre asteriscos *...*, texto de las notas que no existe en Sepúlveda.

- Juan Ginés de Sepúlveda, Obras Completas I. Historia de Carlos V. Libros I-V. Vida y Obra. Estudio Filológico, Bibliografía edición crítica y traducción de E. Rodríguez Peregrina. Estudio histórico de B. Cuart Moner, Pozoblanco (Córdoba) 1995, 50. 
nuscritos, la expresión recogida es: *ad hunc motum suprimendum* y comienza el párrafo.

- V 31: Duplici acie instructa copias e castris educit [copias ipsi silentio castris educunt duplice acie instructa].

- VI 159: Castris Caesarianis [Caesariani, Castris] conjunctis, aut non longo intervalo [intervallo] distantibus, liberius passim vagabantur.

- IX 8: Belli occasiones [occasiones belli].

- XII 2: locus tam munitus erat [tam munitus erat ille locus].

- XIV 36: signa convertere [convertere signa].

\section{Morfológicos:}

\subsection{De número:}

- III 18: *antequam* interciperentur [interciperet].

- IV 7: extra ordinem quae usui sint [essent] imperando vagatur [vagabantur].

- V 19: Oppida et arces praesidio, [praesidiis] firmare [firmarent].

- XII 13: Ab statione discesserant [discesserat].

- XIV 3: Legionarius [legionarios].

2.2. De caso:

Una consecuencia de querer independizar los ejemplos de su contexto es pasar los términos que se han escogido a nominativo:

Nominativo por acusativo:

- III 17 Equites cataphracti [Cataphractos].

- ibid.: Pedites scloppetarii [Scloppetarios].

- IV 5: urbs [urbem] nec loco satis nec opere munita [munitam].

- IV 7: Imperati [imperatos] milites.

- V 23: Pax [pacem] pugnandi conditio [conditionem].

- XIII 4: Belli summa [summam].

- XIV 3: Legionarius [legionarios], con cambio de número.

Nominativo por genitivo:

- I 15: fossis et vallis [ ... I obsessi cum praelium non impetrassent I ... ut ne unus quidem] Numantini [Numantinorum].

- I 18: funditores et sagittarii [funditorum et sagittariorum]. 
- XIII 6: Fabri [Fabrorum] [magnam esse paucitatem, ...] ad opera oppugnationis necessaria.

Nominativo por ablativo:

- I 19: bellum difficillimum [bello difficillimo].

- II 24: speculatores [speculatoribus].

- III 21: Militun veterana manus [Manu].

- IV 14: Expediti sagittarii [expeditis sagittariis.]

- IV 23: tumultuaria manus [manu].

- ibid.: Populares ad arma vocat [Popularibus ad arma vocatis].

- ibid.: collectitia manus [manu].

- V 3: [novo delectu] Novus delectus.

- VIII 20: Calones [Calonibus cunctis ...] et pabulatores [pabulatoribus].

- ibid.: Exploratores et antecursores equites [Exploratoribus et Antecursoribus Equitibus].

- XI 19: Milites [Militibus] sine imperio vagantes [vagantibus].

- XI 31: Tumultuaria praelia [tumultuariis praeliis].

- XII 5: Excubitores [Excubitoribus].

- XIV 5: Armati homines [armatis hominibus].

También se registran otros cambios de casos como:

Acusativo por nominativo:

- III 15: Copias [Copiae ...] hibernorum praesidiique causa *in varia oppida* deducere [deductae].

- III 22: sexcentos [sexcenti] homines reperiunt ex oppidanis.

- VII 8: aditum patefaciunt [aditus patefactus].

Acusativo por genitivo:

- II 24: lllos [lllorum expectavit ...] aggreditur.

Acusativo por dativo:

- III 17: subsidium mittere [subsidio mitteret].

Acusativo por ablativo:

- III 18: tormenta leviora [levioribus tormentis] globesque ferreos [Globisque ferreis] ... convehere.

Genitivo por nominativo:

- II 24: praetoris (praetor quemadmodum iussus fuerat . . . I Ronquilli equitatus [Ronquillus consistit tum bipartito equitatu].

Dativo por ablativo:

- IV 42: Rex Gallus, exercitu reparato [praeficit, ... cum] suis laborantibus opem fert [ferre].

Ablativo por acusativo:

- V 30: custodibus [custodiam]. 


\subsection{De tiempo}

También responde a una intención generalizadora por parte del traductor, o a una reinterpretación, mediante supresión de párrafos y reelaboración de otros, que origina un cambio en la categoría sintáctica del texto.

Infinitivo por forma personal:

Se registran bastantes ejemplos perfectamente explicables desde la intención del traductor de aislar determinadas frases y generalizar su significado:

- III 14: Cum turma expeditorum equitum [mittit, qui paulo longius progressus, ... consisteret] consistere.

- ibid.: Custodias per muros disponere [disposuit].

- III 17: Ad tuendum castellum subsidium mittere [subsidio mitteret].

- III 18: [ut inde commodiore ac breviore] terrestri itinere *cum praesidio*, convehere [conveherentur]. El autor de las notas, una vez comprobado el manuscrito, nos parece que ha interpretado mal la sintaxis oracional.

- III 25: Extremum agmen carpendo adversarios morari [morarentur].

- IV 8: In acie prima versari intra teli jactum venire [intra teli jactum ventum est ... qui in acie prima versabatur].

- IV 9: pari conditione dimicare [dimicarent].

- IV 32: *Oppidum* cum firmo praesidio obtinere [obtinebant]. [oppugnare aggreditur ...] et munitionibus firmare [firmavissent].

- V 1: Amicitiam bellique societatem inire *cum aliquo* [inivit]

- V 4: aggerem excitare [excitavit].

- V 17: Bonam *muri* [ejus] partem demoliri [demolitus est].

- V 19: Oppida et arces praesidio [praesidiis] firmare [firmarent].

- V 21: Ordinem [columna duxisset] ducere.

- V 23: Milites adducere [adducerent].

- V 24: Ad signa sumtis [sumptis] armis convenire [conveniatis].

- V 28: Castra castris conferre [conferrent].

- V 29: Papiam obsidione laxare [laxarent].

- V 30: Castris [ ... I cum suis extra ordinem nec accepta tessera. [Castris ... J excedere [excedebat].

- ibid.: Turmatim centuriatimque vagari [vagabantur].

- VIII 10: Praesidium deligere et constituere [deligebat et constituebat].

- VIII 11: Intra bombardae teli jactum castra castris conferre Icontulerunt].

- ibid: Parum honeste in castra sese [sese in castra] recipere [receperunt].

- VIII 12: Collatis signis [ ... ] dimicare [dimicaret].

- XI 15: Ordinem ducere [ordines ducebant].

- XI 19: Temere vagare [vagarentur].

- XIII 10: Aequato loco dimicare [dimicaret]. 
Infinitivo por participio o gerundio:

- III 15: Copias [Copiae ... J hibernorum praesidiique causa *in varia oppida* deducere [deductae].

- V 31: Murum ariete concutere [concutientium].

- XIII 5: Pari conditione dimicari [dimicando].

Forma personal por infinitivo o participio:

-III 17: Pedites scloppetarii [Scloppetarios] ab equitatu [Procerum ipsoque Velasco intercepti] intercepirentur.

- III 26: Ausus [ausum] *est*.

- IV 3: Milites ... intelligunt [intelligentes].

- IV 23: Populares ad arma vocat [Popularibus ad arma vocatis]. [ferre].

- IV 42: Rex Gallus, exercitu reparato [ ... ] suis laborantibus opem fert

- VII 8: Milites [ ... ] acrius instant [instare], et [ ... ] oppugnationem urgent [urgere].

- ibid.: suffosso muro ceteris aditum patefaciunt [aditus patefactus].

- VIII 10: *Oppida* quae maxime facultatem ad bellum gerendum habent [habere].

- VIII 23: De his a [ab ipsis] Germanis militibus... supplicium sumitur [sumptum].

- VIII 44: *Milites*... a rusticis invadentibus tunicis et subuculis expoliantur [spoliati].

- X 37: In priore parte agminis collocantur [collocati].

- XII 3: Ventilabris arenam [... ] excitant [excitare].

Tiempo simple por tiempo compuesto:

- III 24: equitatus ad Simancas relinquitur [relicta fuerat].

- VI 23: Carris cuppisque objectis [reliquas] vias, paucis ad singulas dispositis jaculatoribus, obsident [obsederunt].

Presente por pasado sin cambio de modo:

- III 22: *Urbis* portam [quae . . .] hasta pulsat [pulsavit].

- III 23: sexcentos [sexcenti] homines reperiunt ex oppidanis ... / ... ex oppidanis reperti sunt].

- ibid.: Inclinatam suorum aciem videns, se fugae mandat Imandavit].

- III 24: ut [ ... ] Valdolitensibus ... immineat [immineret].

- III 25: Agmen acie instructa [... ] consistere jubet [iussit].

- IV 7: extra ordinem quae usui sint [essent] imperando vagatur [vagabantur]. Presenta un cambio de número en la última forma verbal.

- IV 23: Milites ... qui duo signa sequuntur [sequebantur].

- V 18: avertere tentat [tentavit]. 
- V 23: Milites adducere [adducerent] ut [ex] hibernis ad signa et una castra conveniant [convenirent].

- VI 14: Petit ut sibi [ ... ] munitiora l ... ] oppida tuenda tradat [traderet].

- VI 23: Carris cuppisque objectis [ ... I vias, paucis ad singulas dispositis jaculatoribus, obsident [obsederunt].

- VII 12: Perforato muro, ... si forte hostes perveniant [pervenissent], remanent [remanserunt].

- VII 17: Milites sese oppidanorum, castellanorumque opibus alunt [alebant].

- X 15: transverso vallo muniri [ ... I placet [placuerat].

- X 25: *Milites germani* [nostri ... I ex diversis partibus in locum unum conveniunt [convenerant].

Presente por pasado y cambio de modo:

- II 26: adversariorum manum contemnunt [contemnerent].

- ibid.: Citeriores Orospedae Sagoviensiumque jugorum radices obsidet IOrospedam, jugaque Sagoviensia superaturi videbant ad citeriores radices obsideret].

- III 18: Tormenta illinc $[$... I deducta $($... I Burgos deferenda curat [curaret].

- VI 31: Ad [... I oppugnandas munitiones properant [properarent].

- VII 8: Interclusi a tergo caeduntur [caederentur].

- VII 15: Interim IRoma, Ostia, ... I fidei causa in potestatem Caesaris [... ] *plura oppida* permittuntur [permitterentur].

- IX 21: primam *hostium* aciem propellunt [propellerent].

- IX 22: Donec urbis munitionibus muroque succedunt [succederent].

\subsection{De modo:}

Además de los que acabamos de examinar en que el cambio es de tiempo y modo, se detectan ejemplos donde el cambio de modo se concentra en formas verbales de pasado: derent].

- III 17: Pedites scloppetarii [Scloppetarios] qui vias obsidebant [obsi-

- V 17: Pleraque tormenta et plurimum bellici apparatus Papiam contulerant [contulissent, recepta Papia].

- VI 31: Tanta [quanta] erat [esset] fossarum vallorunque brevitas, ut [qua tam] facile Esfortiani [Sfortiani] tabulis quibusdam [...] sublevati evadere potuerint [potuerunt]. [ambiret].

- VII 16: imperii summam *Germanorum* comitiis militaribus ambibat 


\subsection{De voz:}

- III 18: *antequam* interciperentur [interciperet].

- III 22: sexcentos [sexcenti] homines reperiunt ex oppidanis ... [...ex oppidanis reperti sunt $]$.

- V 3: diruta reficere [reficiendi].

\section{Sintácticos:}

Para resaltar el contenido de algunas palabras:

- V 11: *Oppidum per deditionem recipere* [Vercellae per Oppidanorum deditionem receptae]. En esta situación podemos pensar que el traductor quiere facilitar la categoría sintáctica de algunas palabras y, en vez de [Vercellae ... receptae], propone, incluso incluyendo la traducción: *Oppidum per deditionem recipere*, es decir, «tomó la plaza que se le entregó».

- VI 9: A nostris [Per nostros] [irrupisset, tamen a majore nostrorum Equitum numero] qui transvectos invaserant *equitatus* circumventus. En el texto que recoge el traductor queda evidenciada la importancia de: A nostris y de *equitatus*, que son los términos que se oponen.

\section{SUSTITUCIONES:}

\section{De unos términos por otros:}

- III 13: Centurio [quidam occubuit, in cujus tunicae manica Sacer Calix argenteus repertus fuit, quem Fano Torlobatonis oppidi ab ipso et] *cum* manipularibus. Al omitir toda la explicación precedente, cambia la preposición $a b$ por cum.

- V 30: custodibus [custodiam]. Presenta una sustitución del término.

- V 33: Germanorum acies [genibus flexis Deum Christiano more, ut res feliciter eveniret comprecata] Helvetiorum obviam phalangem adoritur, Hispanis jaculatoribus latera claudentibus atque eminus rem gnavius Ignaviter] gerentibus. La sustitución se produce entre dos adverbios, gnavius, en grado comparativo, se emplea en lugar del positivo gnaviter.

- VI 14: Ad bellum impendens propulsandum opportunissimas *arces $i b i *$ [sibi] tradat [traderet]. Comprobamos aquí que el traductor escribe: *arces $i b i *$, sin embargo en Sepúlveda lo que se lee es [sibi]. A nuestro parecer puede tratarse de un error motivado por la inclusión del término arces que en Sepúlveda aparece más arriba. 
- VI 30: Facta eruptione per hostes qui parum frequentes arcem obsidebant, evadentes Mediolanum incolumes [cuncti] perveniunt. En este texto cuncti ha sido sustituido por incolumes.

2. De topónimos o antropónimos

Por otro erróneo:

- III 20: Signis infestis Burgos [Victoriam] contendit. El comentarista que, en este caso concreto, está interesado en resaltar el sentido de infestis comete, a nuestro parecer, un error en la utilización del topónimo.

- VI 29: Per murum, qua parte *Marramaldus* [Vistarinus] cum suis manipularibus excubias habebat. Tambien creemos que se debe a un error el cambio que ofrece el texto donde el autor de las notas ha cambiado el nombre del conspirador [Vistarinus] por el del engañado *Marramaldus*.

Por otro topónimo mós genérico:

- III 12: Copiis coactis *Valdolitum* [Petrus Velascus Methymnam] contendit. La utilización de un topónimo más general omite información geográfica importante en la enumeración de hazañas y personajes.

Por un sustantivo mós genérico:

Hay una tendencia por parte del autor de este manuscrito, a sustituir una referencia concreta a un lugar o a un determinado personaje, por una generalización más o menos indeterminada.

- III 10: [Affuit Alvarus Osorius Asturicae Marchio, cum Petro, maximo natu filio, Alfonsus Pimentellus, Beneventi, Fernandus Sylva, Centumfontium, Jacobus Henricus Gusmanus] *atque inter ipsos* Albaelistae [Albelistae, Franciscus Quignonius, Lunae, Henricus Henriquez, Almiranti frater, Rivadaviae Alvarus Moscosus, Altamirae] comes [Comites]. Sustitución de una relación de antropónimos por la expresión globalizante: *atque inter ipsos* con la explicitación concreta de uno de ellos: Albaelistae ... comes.

- V 1: [cum populo Veneto] Amicitiam bellique societatem inire *cum aliquo* [inivit]. Se generaliza en cum aliquo la referencia especifica del texto original: [cum populo Veneto].

- V 11: His levioribus certaminibus et accepto nuper ad *Bononiam* [Robecum Castellum] incommodo. El traductor sustituye el topónimo más concreto Robecum Castellum por la ubicación más generalizada Bononiam.

- V 16: [magnisque itineribus Mediolanum, ut regem quam maxime poterat properantem anteverterent, reverti contendunt; tantumque fuit Militum studium, ut a Massilia profecti, Papiam vicenis Castris pervenirent et quo die Rex] Cum agmine primo [magna celeritate usus, Vercellas attigit, hoc Borbo- 
nius, et Marchio Piscariae, cum Equitibus et Hispano, atque Italico Peditatu, ab Alba, usque ad Viqueriam, quod Oppidum est ad Padi ripam quadraginta passuum millia, conficerent] *Mediolanum pervenire* Germanis [intervallo] itineris diurni subsequentibus. Con un lacónico *Mediolanum pervenire* resume el traductor todo un párrafo que describe más detenidamente el viaje.

- V 18: Fluvium [Ticinum], qui [fluvius] Papiam, qua murus erat infirmus et oppidum parum munitum, alluit, avertere tentat [tentavit]. Sustitución del hidrónimo Ticinum, por el genérico fluvium.

Por milites:

- VI 38: Cum *militibus* [mille circiter Hispanis Germanisque] Romae conscriptis. El comentarista sustituye mille circiter Hispanis Germanisque por un genérico militibus.

Por oppidum/oppida:

- III 15: Copias [Copiae, partim Symancas, Torlobatonem, Villalvam, Methymnam Rivi sicci, et Portillum, Castella et Oppida circum Valdolitum] hibernorum [hybernorum] praesidiique causa *in varia oppida* deducere [deductae]. Todos los topónimos que determinaban copias se sustituyen por el generalizador oppida.

- IV 32: *Oppidum* cum firmo praesido obtinere [obtinebant] [oppugnare aggreditur; sed parte Urbis expugnata, cum se Galli citra pontem, quo Parma fluvius cognomine Urbem interfluens committitur, recepissent] et munitionibus firmare [firmavissent]. Asీ en este capítulo *oppidum* indeterminado sustituye al topónimo concreto del original que es Parma.

- VII 15: Interim [Roma, Ostia, Civitasvetus, Parma, et Placentia] fidei causa in potestatem Caesaris [Caroli Caesaris] *plura oppida* permittuntur [permitterentur]. Se ha omitido el nombre de las ciudades, que ha sido sustituido por plura oppida.

- VIII 10: [Nos Arces, et Urbes, omnia denique loca munita obtinemus, quorum] *Oppida* quae maxime facultatem ad bellum gerendum habent [habere]. En esta nota con la introducción de *oppida* generaliza una enumeración más detallada: INos Arces, et Urbes, omnia denique loca munita optinemus].

3. De deícticos por antropónimos, topónimos, otros deícticos o viceversa:

Deícticos por antropónimos u otro sustantivo:

- III 6: Cum militibus qui erant *Duci Najarensi ad Navarrae* lei ad illius Regni] praesidium attributi. Frente a lo recogido por Sepúlveda, el traductor suple el anaforico y el demostrativo por Duci Najarensi ad Navarrae. 
- III 12: Relictis his locis Villalpandum [Comestabilis ditionis] oppidum quod [tunc] *a comestabili* [ab illo] defecerat. Se omite el determinante de oppidum: Comestabilis ditionis, que por otra parte queda explicitado en a comestabili y se sustituye el deíctico ab illo del original.

- V 17: Bonam *muri* [ejus] partem demoliri [demolitus est]. El traductor, pensamos que por la posible interpretación del término, ha sustituido el anafórico, que aparecía en el texto de Sepúlveda para evitar la reiteración, por el sustantivo muri al que Sepúlveda hace referencia en otro contexto.

Sustantivo por deíctico: nebantur.

- III 13: [Ab horum enim legatis] Torsillae *ab illis* cum praesidio te-

Demostrativo por otro más cercano:

- III 18: Tormenta illinc [hinc] deducta [in Urbem Victoriam, atque inde] Burgos deferenda curat.

\section{OMISIONES:}

La comparación de los textos muestra que las consecuencias, que se pueden derivar de la «supresion» de una parte del texto original, son de diferente matiz, ya que puede originar una interpretación distinta del mismo y, sobre todo, lo que se produce es una disminución de la información proporcionada:

\section{Del sujeto:}

- III 12: Copiis coactis *Valdolitum* [Petrus Velascus Methymnam] contendit. En este caso el sujeto estaba explicitado por el antropónimo Petrus Velascus.

- ibid.: Quas copias [Petrus Gyron] tribus castellis [Torfumo, Villagarcia, Villabraximal prope Methymnam adversariosque collocaverat, unde Methymnensem agrum incursionibus infestabat.

- III 25: [Bis praelium committendi gratia] Agmen acie instructa [Joannes Padilla, urgentibus adversariis] consistere jubet [iussit]. Además del sujeto, se suprimen especificaciones expresadas por diversos complementos.

- V 13: [Almirallius] ex Novaria copias instructas Romagnum deducit. El texto de Sepúlveda nos informa de un Almirallius, omitido por el traductor y que realiza la acción verbal.

- V 31: Duplici acie instructa copias e castris educit (copias ipsi silentio castris educunt duplice acie instructal; el autor de las notas elimina el sujeto ipsi $y$ pasa el verbo a singular. 


\section{De complementos:}

- I 16: concitato agmine [patentibus portis, ingenti cum tumultu] erumpunt. Se han obviado los detalles que se explicitaban mediante complementos circunstanciales.

- II 27: Fonseca [Antonius, tum] spe bombardis potiendi dejectus, se suprime el praenomen.

- III 8: Novo delectu [suas] copias augent, [hisque Petrum Gyronem, Ureñae Comitis natu maximum filium, suam operam pollicentem, cum imperii] *quibus* cum imperii summa *Gironem* praeficiunt. Se omite el posesivo [suas], desapareciendo un matiz determinante de este adjetivo, que no es accidental; [Gyronem] sintetiza el personaje omitiendo su genealogía; el texto omitido queda recogido en la oración de relativo que se introduce.

- III 12: Falcium Marchio cum filiis et bono veteranorum militum comitatu [ex Navarra] proficiscitur [profectus].

- ibid.: Quas copias [Petrus Gyron] tribus castellis [Torfumo, Villagarcia, Villabraximal prope Methymnam adversariosque collocaverat, unde Methymnensem agrum incursionibus infestabat. [Sed post adventum Petri Velasci] Relictis his locis. Se omiten los antropónimos: [Petrus Gyron], los topónimos: [Torfumo, Villagarcia, Villabraxima] y alguna otra información: [Sed post adventum Petri Velasci].

- III 25: [Bis praelium committendi gratia] Agmen acie instructa [Joannes Padilla, urgentibus adversariis] consistere jubet [iussit], se suprimen especificaciones expresadas por diversos complementos.

- IV 14: jaculatoribus [ab utroque latere ex Vineis] impune agmen impetentibus et [magnum] detrimentum inferentibus.

- IV 24: *Agminis* [acieque instructa et] fronte ex industria ad speciem paulo latius explicata ceteros superne hostes invadere jubet, ipse cum equitatu (eodem tempore a latere] Germanos [circa Montis cacumen] adoritur. Observamos la supresión de dos aclaraciones: eodem tempore a latere referida a cum equitatu y circa Montis cacumen que modifica adoritur.

- V 23: Milites [ex Fonterrabiae praesidio] qui duo signa sequuntur [sequebantur].

- VI 14: Petit ut sibi [Arces omnes] munitioralque] oppida tuenda tradat. En este caso se ha suprimido el objeto directo.

\section{De sintagmas oracionales:}

- I 15: fossis et vallis [ne, quod frustra tentaverunt, erumperent] obsessi cum praelium non impetrassent [in ultimam se rabiem, furoremque con- 
verterunt; desperatisque rebus, ne in potestatem hostium devenirent, duces suos, seque et Patriam ferro, veneno, sujectoque igne peremerunt, sic ut ne unus quidem] Numantini [Numantinorum superfuerit]. En las notas recogidas en el manuscrito no se hace mención a la masacre que los propios numantinos realizaron en sus filas: ne in potestatem hostium devenirent, $y$ que relata Sepúlveda con términos muy bien elegidos: duces suos, seque et Patriam ferro, veneno, sujectoque igne peremerunt, concluyendo con una expresión globalizante, que resulta significativo que haya sido omitida por el traductor: qui vinctus ducerentur, nec de alio fuerit quam de nomine triumphus.

- Ibid. Numantia (ut Lucius Florus scriptor romanus tradit, I sine muro sine turribus. Al suprimir la oración de ut, se elimina la fuente literaria: Lucius Florus, que Sepúlveda proporciona.

- II 24: praetoris (praetorianus equitatus, nisi ut civium vitae parceretur, praetor quemadmodum iussus fuerat edixisset, parumper igitur Sagovienses insectatus] Ronquilli equitatus [Ronquillus consistit tum bipartito equitatuj. La supresión de texto y la sustitución de praetorianus por praetoris provoca una original interpretación del texto al situar como sujeto a equitatus, refiriéndose en segundo lugar a Ronquillus, quien estaba al frente y, según Sepúlveda, da la orden de ataque.

- ibid.: lllos [lllorum expectavit et multo iam die flumen traiectos] aggreditur. El autor de las notas informa simplemente de la acción realizada, omitiendo dos momentos claves expresados por dos formas verbales expectavit y traiectos.

- ibid: aestu fatigatam [(erat enim mensis Julius et diei tempus meridianum)]. Se ha suprimido la oración explicativa de aestu, puede que por no ser necesaria.

- II 26: Ex altera Orospedae parte consederunt [donec Praetor idem, qui cognito illorum Consilio, Niviam suos reduxit, discessisse nuntiatur. Tunc vero juga transgressi, in Spinarium Sagoviensis Agri Vicum, citra Urbem passuum millibus viginti evaserunt, quo paulo post ducentos homines a Madritiensibus missos, Joannes Zapata Praefectus per invia Montis cacumina deduxit, et cum Toletanis conjunxit.] Huc quoque convenit Sagoviensium manus Icui ab eo tempore Joannes Bravus homo nobilis praefuit; auctoque numero ad Peditum quatuor millia, et Equites centum, omnes Niviam in Praetorem Ronquillum movent]. Ille vero [ad Riomorum fluvium, de quo supra mentionem fecimus, venientibus occurrit, atquel eos adequitando et carpendo a meridie [circiter] usque ad noctem solicitavit [; tunc quoque Praefectis Equitum, quod a pugna prohiberentur, indignantibus. Sed ea nocte populares Niviae, Praetor ad Miguelivagnum vicum duobus inde passuum millibus consedit; ac postero die, qui fuit quadragesimus octavus, quam Niviam venerat, ut jussus 
erat, discessit, ad Arevalumque reductum, Equitatum Antonio Fonsecae, tradidit, qui obviam ipsi cum paucis, quos coegerat, Equitibus processerat. Hunc enim Carolus discedens, Regiis Copiis omnibus, si quid tumultus oriretur, praeesse jusserat]. In Methymnam Campestrem [Erant Methymnae, quae Campestris cognominatur] tormenta multa [quae huc jussu Fernandi et Isabellae Principum] collata fuerant. El autor de las notas reseña tan sólo los acontecimientos, eliminando todas las explicaciones intermedias. Es ésta una postura muy generalizada.

- II 27: Per interrupta murorum [in oppidum, ut metum incuteret oppidanis] irrumpit. Al traductor no le interesa recoger in oppidum, ni la finalidad de la irrupción: ut metum incuteret oppidanis.

- III 10: Ad Almirantum [ad quem] *et exercitum* proceres cum suo quisque comitatu frequentes convenerunt. En este texto el traductor suprime la oración de relativo [ad quem] por la repetición del antecedente: $A d$ Almirantum.

- III 14: Cum turma expeditorum equitum [mittit, qui paulo longius progressus, in itinere quod ducit a Villalpando consisteret] consistere. Se ha eliminado la especificación in itinere, así como la oración de relativo que especifica concretamente itinere.

- III 17: Ars [quoque] munitissima, intentata modo oppugnatione, per ignaviam praefecti dedita [eodem die] in popularium potestatem pervenit qui stativa ibidem habere constituerant [propter loci opportunitatem ad Proceres qui Torsillis continebantur infestandos, atque ipsum Oppidum, quod inde abest passuum duodecim millibus, per occasionem oppugnandum, et Commeatibus intercludendum. Cujus rei gratia] Pedites scloppetarii [Scloppetarios] qui vias obsidebant [obsiderent] [quotidiana consuetudine dimittebant, donec horum circiter quinquaginta] ab equitatu [Procerum, ipsoque Velasco intercepti] intercepirentur. De nuevo se toman las líneas generales del relato eliminando todas las aclaraciones intermedias.

- III 20: Oppidani [ab eodem Jacobo, ut protinus Urbe cum suis decederet] impetrarunt [his submotis facilius Comitis animum placari posse existimantes; nec ipsos opinio fefellit. Nam illis digressis, Treviñumque Najarensis ditionis oppidum migrantibus, pax Civitati data est certis conditionibus; quarum illa fuit,] ut portis patefactis Comitis exercitus signis militaribus explicatis per urbem quasi victor [sine injuria tamen et maleficio] transiret. Aquí se refleja el mismo hecho que en el texto anterior.

- ibid.: Signis infestis Burgos [Victoriam] contendit, et [intermisso mille circiter passuum spatio, in planitie, quae Arriaga dicitur, consedit. Sed dum] oppidum oppugnare parat, viri .... ad eum in Castra legati de pace mittuntur. Observamos que el traductor mediante la omisión de una parte del tex- 
to, ocasiona un sincretismo del desarrollo de la acción: signis infestis Burgos contendit et oppidum oppugnare parat, que en el original no se da.

- III 24: ut leo Praesidio Comes Oñati non modo Castellum id ad bellum gerendum peropportunum custodiret, sed] Valdolitensibus [etiam] immineat [immineret]. Aquí sólo interesa la oración de immineret, que en el manuscrito ha cambiado de pasado a presente, por lo que se elimina toda la primera oración y los correlativos de la segunda con aquella: sed y etiam.

- III 25: Extremum agmen carpendo adversarios morari [morarentur]. [Proceres cum reliquo Equitatu non longo intervallo insequuntur, Peditibus subsequi properareque jussis. Bis praelium committendi gratia] Agmen acie instructa [Joannes Padilla, urgentibus adversariis] consistere jubet [iussit]. Además de sintagmas oracionales, se suprimen otras especificaciones expresadas por diversos complementos.

- IV 3: Milites [circiter septingenti, qui fuerant] per oppida in praesidium dispositi gallorum multitudini se pares esse non posse intelligunt lintelligentes I. Se suprime el pronombre que inicia la oración de relativo y la parte auxiliar del verbo en forma personal que queda, de este modo, convertido en participio.

- IV 5: Moenium [-que] infirmitate animadversa, ut hostem [qui in proximo consederat] oppugnatione deterreret.

- V 13: Galli [spe Rhetiorum subsidii, amissoque Abbiagrasso, unde commeatu bonam partem sublevabantur et] paene cunctis ex partibus interclusi.

- V 30: Per mediam hostium stationem vadunt et [quinam mortales essent rogantibus, ad tesseram petentibus Gallis, se Joannis Medicae Equites esse respondent] custodiam [que] fallunt.

- VI 31: Tanta [quanta] erat [esset] fossarum vallorumque brevitas, ut [qua tam] facile Esfortiani [Sfortianil tabulis quibusdam [quas secum deportaverant] sublevati evadere potuerint [potuerunt]. Se ha eliminado la oración de relativo que explica tabulis quibusdam.

- VII 8: Milites [hortante Joanne Urbina et extremum periculum, si gradum retulissent, denuntiante] acrius instant [instare], et [majore jam non solum studio, sed etiam indignatione] oppugnationem urgent [urgere].

- VII 11: Trans Tiberinam Urbis partem, adjunctis Hispanis, cum Italica manu [cum Italica cui praeerat Manu, paucis quibusdam Hispanis adjunctis, trans Tiberinam Urbis partem] circumire coepit.

- VIII 12: Collatis signis [antequam hostis in Campaniam perveniret] dimicare [dimicaret].

- VIII 20: Calones [Calonibus cunctis in certum locum paulo remotiorem procedere, Fernando Gonzagae, cum quadingenties Equitibus levioris Ar- 
maturae, et ducentis Cataphractis, Peditum Germanorum quatuor millia, milleque Hispanos attibuit, cumque his proficisci] et pabulatores [pabulatoribus].

- IX 5: Primam aciem [quae Hispanorum erat,] in eos [Germanos] immittit.

- IX 18: Cum [Armatorum tribus millibus] magno commeatu adventare.

- X 15: transverso vallo muniri let valido praesidio firmari ad Turcarum navigationem impediendam. Carolo, Fernandoque] placet [placuerat].

\section{ADDENDA}

Estas inclusiones sustituyen a una perífrasis más explícita del original:

- I 18: Mithridates [Rex Asiae praepotens] Romanorum armis aflictus [afflictus] *auxilium poscit*. Se ha resumido la última parte en el «auxilium poscit que, pensamos, no cambia el sentido de la frase, aunque reduce la información.

- II 28: Ea quoque manus equitum peditumque ex parte dissoluta est atque Hadrianus *Cardinalis* sine ullo militum praesidio relictus praeter paucos quos custodiae gratia circa se habere consueverat. En este capítulo el traductor, para dar mayor énfasis a la figura de Adriano, añade: Cardinalis, cargo que excede a la explicación de Rodriguez Peregrina ${ }^{7}$, quien lo considera Obispo de Tortosa

- III 10 Ad Almirantum [ad quem] *et exercitum* proceres cum suo quisque comitatu frequentes convenerunt. Se añade *et exercitum*, implícito en el texto que seguía en el original.

- III 22: *Urbis* portam [quae Sancti Joannis cognominatur] hasta pulsat [pulsavit]. Se incluye el término *urbis*, aunque en el original no se registra para nada.

- IV 7: Armaturae levioris *equites*. Al suprimir el contexto anterior, se ha visto obligado a añadir aquí equites.

- IV 24: *Agminis* [acieque instructa et] fronte ex industria ad speciem paulo latius explicata ceteros superne hostes invadere jubet, ipse cum equitatu [eodem tempore a latere] Germanos [circa Montis cacumen] adoritur. De nuevo un addendum: *agminis*, que sustituye otro texto del original, en este caso: acieque instructa.

- IV 25: [Erant duae magnae Catenae transversae in fluvio Bajonam alluente, quae additum Navium impediebant;] Ad catenas [has] *fluvii Bajo-

${ }^{7}$ op. cit. Índice de nombres, 1023. 
nae* infringendas dentata ferramenta aeneaeque bombardae, quibus illa erant ex naviculis contorquenda, ingeniose comparantur. Se introduce un addendum para resumir un párrafo explicativo anterior, lo que hace que cambie una vez más el sentido del texto original. Bayona es la ciudad y no el río.

- VII 16: imperii summam *Germanorum* comitiis militaribus ambibat [ambiret]. El traductor se ve obligado a añadir un Germanorum que en Sepúlveda estaba explicitado unas líneas antes.

- VIII 1: Copiis coactis ... qui cum praesidio Mediolanum obtinebat ... *Milites* Germani, facta secessione, tumultuari coeperunt y

- VIII 44: *Milites* domum redeuntes a rusticis invadentibus tunicis et subuculis expoliantur [spoliati]. El traductor, para una mejor comprensión de los textos, añade en ambos el término milites.

- XI 22: Copiis intra et extra *vicum* circumjectis. Hay que incluir un vicum que en el texto de Sepúlveda no hacía falta explicitar, puesto que estaba en la frase inmediatamente anterior.

- IX 21: Propere ad arma concurrunt, [tantisque animis Italos adoriuntur] et [ut primo impetu illorum] primam *hostium* aciem propellunt [propellerent] . Al omitir una frase en la que se encuentra recogido un gentilicio: Italos, el autor de las notas se ve obligado a introducir el término hostium.

\section{REELABORACIONES:}

- II 26: Citeriores Orospedae Sagoviensiumque jugorum radices obsidet [Orospedam, jugaque Sagoviensia superaturi videbant ad citeriores radices obsideret]. El traductor reelabora el texto a partir de ad citeriorem radices, opina que a ambos ejércitos que preparan y esperan el ataque, les afecta la expresión citeriores radices obsidet, cuestión no tratada así por Sepúlveda, quien se está refiriendo a dos pueblos los Toletani, quienes van a cruzar a través de Orospedam, y los Segovienses, que van a situarse ad citeriores radices sin cruzarla,

- III 18: Tormenta illinc [hinc] deducta [in Urbem Victoriam, atque inde] Burgos deferenda curat [curaret. Is jussa diligenter administrans] tormenta leviora [levioribus tormentis] globesque ferreos [Globisque ferreis] [et caeteris quae Tormentis usui sunt, per terram statim quo properantius deportarentur, missis, septem graviora Tormenta in Navem imposuit, cumque his ipse Bilbaum navigavit, ut inde commodiore ac berviore] terrestri itinere *cum praesidio*, convehere [conveherentur] [Hoc Torsillas nontiato, Populare Consilium Petro Ayalae Comiti Salvaterrae per literas mandavit, daret operam guam maxime posset, ut Tormenta] *antequam* interciperentur [interciperet] 
[nec ulla ratione in adversariorum Castra perferri sineret. Nam is ex Proceribus partes Popularium pertinaciter ad Cantabriam fovit, quemadmodum ad Asturiam et Legionem urbem Ramirus Nuñez Guzmanus, qui Torali oppido aliisque Castellis Vicisque per eam regionem imperitabat. Hic enim se ducem praebuit hujus tractus Popularibus, sive quod illorum publicam causam probabat, sive studens veteribus factionibus, ut a Comite Lunae, quem ab Urbe Legione depulit, dissentiret. Fuerat autem Comes Salvaterrae a Consilio Torsillano omnis ejus tractus, qui ab Agro Burgensi, usque ad Oceanum, et Fonterrabiam pertinet, dux et Praeses constitutus, cujus impulsu hae regiones magna ex parte tumultuabantur, et praefecturae veteris Castellae, quas $\mathrm{Me}$ rindades appellant, a Comestabili, cujus erant in clientela, defecerant, et illius auctoritatem sequebantur. Is cum literas Concilii, de quibus supra diximus, accepisset, praemittit ex suis, qui caetera Tormenta, quae ex Fonterrabia per teram devehebantur, interciperent, ipse celeriter, coacta per Gonzalum Barahonam suum Praefectum circiter decem millium armatorum manu, cum his in Vallem Arratiam movet, qua septem illa graviora Tormenta ad Bilbaum exposita a Sanctio Velasco cum praesidio convehi nuntiabantur. Sanctius, cognito de Comitis et tantae manus adventu, cui pars esse non poterat, TormentaJ vehiculis detracta. Se puede observar la reelaboración de todo un párrafo en el que se dan muchos de los fenómenos que hemos analizado anteriormente. El texto que ofrecen las notas es: Tormenta illinc deducta Burgos deferenda curat tormenta leviora globesque ferreos terrestri itinere *cum praesidio*, convehere *antequam* interciperentur vehiculis detracta.

- III 22: Victorienses ((cognito) Comitis Consilio, ad obsistendum sese comparant,] habito [habitoque] censu sexcentos [sexcenti] homines reperiunt ex oppidanis qui arma ferre possint [qui arma ferre possent, ex oppidanis reperti sunt]. De nuevo la reelaboración se ha hecho a base de diferentes fenómenos como cambio de caso, tiempo o voz.

- IV 7: Triplici acie instructa *contendit* ljam appropinquantibus opponunt] [quarum prima Cantabrorum erat; altera Vaccaeorum, et Celtiberorum, regionumque finitimarum, in qua Jacobus Henricus curabat; tertia Militum veteranorum, quibus praeerat Gutierrus Quixada. Nam Comestabilis, et Almirantus, et Dux Najarensis nunc cum Equitatu erant, qui paucis exceptis separatim constiterat, nunc] extra ordinem quae usui sint [essent] imperando vagatur. [vagabantur] [Postquam] In acie prima versari intra teli jactum venire (intra teli jactum ventum est, Galli pugnam tormentis ineuntes, nonnullis prostratis, magnum terrorem nostris, praesertim nuper conscriptis, incusserunt (nam veterani interriti praelium iniere) ita ut Dux Najarensis, qui in acie prima versabatur]. La reelaboración se opera también en este texto, así con triplici acie instructa emplea contendit frente 
a [iam appropinquantibus opponunt]; a continuación, elimina la descripción de los componentes de cada una de las líneas y de quiénes eran los que, de forma extraordinaria, estaban al frente de las mismas por estar sus jefes habituales con la caballería, y retoma la narración un poco más adelante: extra ordinem quae usui sint imperando vagatur. El párrafo siguiente vuelve a ser comprimido en una breve frase: in acie prima versari intra teli iactum veni$r e$, cambiando, en cierta mamera, el sentido original del texto.

- IV 42: Rex Gallus, exercitu reparato [huic Almirallium cum summa imperii praeficit, et in Italiam properare, et cum] suis laborantibus opem fert [ferre]. La supresión de una parte del original obliga al autor de estas notas a un cambio en el tiempo verbal.

- VI 1: Italiam bello vexare [bello, quo jam pridem Italia fuerat continenter vexata]. El paso del verbo a infinitivo implica un cambio de voz que exige una reelaboración del texto.

- VI 13: Copias quae diversae agebant, Salutias et Astam evocat. [Salutias et Astam, copiis quae diversae agebant evocatis], aqui ha sustituido el ablativo absoluto por una oración en forma personal.

\section{REINTERPRETACIONES}

- VIII 10: *Galli milites nec* [militares diurnos ac nocturnos labores] aestus, nec *servitia* [pervigilia] pati possunt. Se ha preferido suprimir la expresión: diurnos ac nocturnos labores y sustituir el término relacionado con la misma, pervigilia, por servitia, que tiene un referente más amplio.

- XI 21: Equitatus hostilis [hostium Equitatum]. El autor de las notas ha optado por pasar el acusativo equitatum a nominativo y sustituir el sustantivoadyacente hostium por un adjetivo adyacente, hostilis.

Hasta aquí la descripción de las diferentes alteraciones que hemos observado en el manuscrito con respecto al original de Sepúlveda. Las innovaciones nos han resultado interesantes y curiosas. Es una lástima que este diccionario, que aporta, como ya hemos indicado en otros trabajos, traducciones muy oportunas, no lleve aneja una pequeña explicación dando razón de estas puntualizaciones.

De su análisis deducimos que son las matizaciones que un conocedor de la materia podría aventurarse a hacer, siempre con el riesgo de algún atrevimiento, y de las que se pueden obtener matices que favorecen el estudio crítico de esta obra. 